\title{
The X-Bolt: A Biomechanical Study with this New Design Variation of the Dynamic Hip Screw (DHS)
}

\author{
Francis O'Neill ${ }^{* *}$, McGloughlin $\mathrm{T}^{2}$, Coffey $\mathrm{JC}^{3}$, Walsh $\mathrm{M}^{4}$, Condon $\mathrm{F}^{5}$ and Lenehan $\mathrm{B}^{5}$
}

${ }^{1}$ Centre for Applied Biomedical Engineering Research (CABER), Department of Mechanical and Aeronautical Engineering and Materials and Surface Science, Institute (MSSI), University of Limerick, Ireland.

${ }^{2}$ National University of Ireland, M.Eng Sc, National University of Ireland, Ph.D. Trinity College Dublin

${ }^{3}$ Department of Surgery, Consultant General and Colorectal Surgeon, Graduate Entry Medical School, University of Limerick, MidWestern Regional

hospitals, Limerick, Ireland

${ }^{4}$ Doctor of Philosophy (Mechanical Engineering), University of Limerick, Bachelor of Engineering, (Mechanical), University of Limerick

${ }^{5}$ Consultant Orthopaedic Surgeon, Midwestern Regional, Orthopaedic Hospital Croom / Midwestern Regional Hospital, Dooradoyle Limerick

\begin{abstract}
Objective: The objective of this study was to test a newly developed implant for the treatment of intertrochanteric fractures, the X-Bolt, against the current gold standard, the Dynamic Hip Screw (DHS), by comparing the amount of energy required to cause failure of both of them.
\end{abstract}

Methods: Push out studies were performed with both the dynamic hip screw and the X-Bolt in an artificial bone substrate in the form of polyurethane foam blocks, which have predefined mechanical properties. These push out studies were performed as a means to investigate each implants resistance to 'cut out' as this is the most common mode of failure with the DHS.

Results: The results demonstrate that the X-Bolt produced a force displacement curve with a different pattern of failure than the DHS. The X-Bolt initially required less energy to move it within the test material, than the DHS. However, the further the X-Bolt advanced within the test material, the greater the resistance and as this was the opposite as to what occurred with the DHS, the X-Bolt eventually required more energy than the DHS to advance through the test material and fail due 'cut out'.

Conclusion: The X-Bolt is a new concept with regard to fixation of intertrochanteric fractures. It produces a different force displacement curve than the dynamic hip screw. However further investigations are necessary before the true potential of this new implant is known.

Keywords: DHS; X-Bolt; Intertrochanteric Fracture

\section{Introduction}

Hip fractures are one of the most common fractures in the elderly population [1]It has been estimated that the annual number of hip fractures will reach 2.6 million worldwide by the year 2025 [2] and in the USA, results show that $49 \%$ of hip fractures are intertrochanteric fractures [3]. The Dynamic hip screw (DHS) was introduced by Clawson (1964) and remains the implant of choice for the treatment of intertrochanteric fractures [4]. It is a two piece device that consists of a large diameter cannulated lag screw which articulates with a side plate and barrel [2].

The rate of complications associated with internal fixation of intertrochanteric hip fractures vary with failure of fixation rates reported at between $5 \%$ and $23 \%[4,5]$. The most common mode of fixation failure with the dynamic hip screw is collapse of the neck shaft angle into varus, leading to extrusion, or so called cut out of the screw from the femoral head [4]. Modes of failure have been well studied, the variables involved identified and quantified, leading to an overall improvement in surgical technique and a reduction in failure rates such that Chirodian et al. [6] reported a total rate of fixation failure of $3.2 \%$ with a cut out rate of $1.9 \%$. There have been many efforts to improve on the DHS lag screw design to reduce the 'cut out' rate even though this rate is relatively low. These attempts have included the Talon Hip Screw [7] and augmenting the lag screw with cement or a coating of hydroxyapatite [8]. However although these design variations have their benefits, they also have complications that prevent them from being widely adopted. Against this background, the X-Bolt was developed which is another new design variation of the lag screw. The purpose of the $\mathrm{X}$-Bolt is to improve bone anchorage and so hypothetically reduce the "cut out" rate.

The X-Bolt as demonstrated in Figures $1 \mathrm{a}$ and $1 \mathrm{~b}$ comprises of 4 parts: an inner shaft with threads of reversing directions; an outer sleeve with an expandable section and a top nut that provides compression from the superior end. Rotation of the inner bolt compresses deforms and expands the outer sleeve.

The points of fixation are widely spaced to spread the load as it has a $25 \mathrm{~mm}$ wing span on full deployment. The objective of this study was to compare the amount of energy required to cause failure of the X-Bolt and the Dynamic Hip Screw (DHS) at their point of fixation at the bone implant interface and therefore determine which device offered the greater resistance to 'cut out'.

\section{Methods}

"Push out" tests were performed to investigate the failure of these

*Corresponding author: Francis O'Neill, Mb Bch MRSCl, Aughavoona House, Garryspillane, Co Limerick, Ireland, Tel: 087 7550420; E-mail: fneill09@yahoo.com

Received November 14, 2011; Accepted December 30, 2011; Published December 30, 2011

Citation: O'Neill F, McGloughlin T, Coffey JC, Walsh M, Condon F, et al. (2012) Oral Malodor: A Common Oral Problem. J Bioengineer \& Biomedical Sci 2:110. doi:10.4172/2155-9538.1000110

Copyright: ( 2012 O'Neill F et al. This is an open-access article distributed unde the terms of the Creative Commons Attribution License, which permits unrestricted use, distribution, and reproduction in any medium, provided the original author and source are credited. 


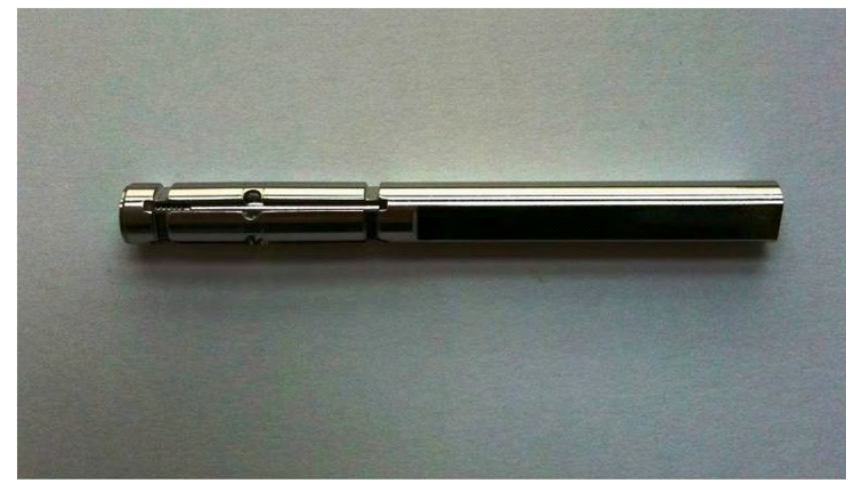

Figure 1a: X-Bolt Closed.

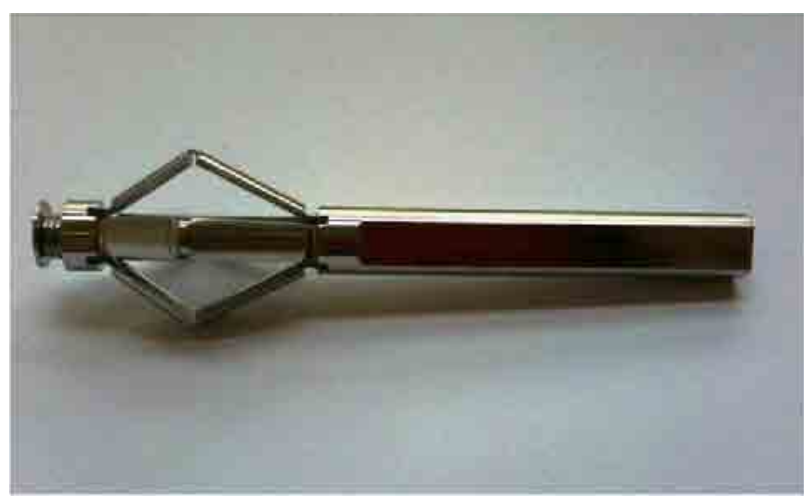

Figure 1b : X-Bolt Opened.

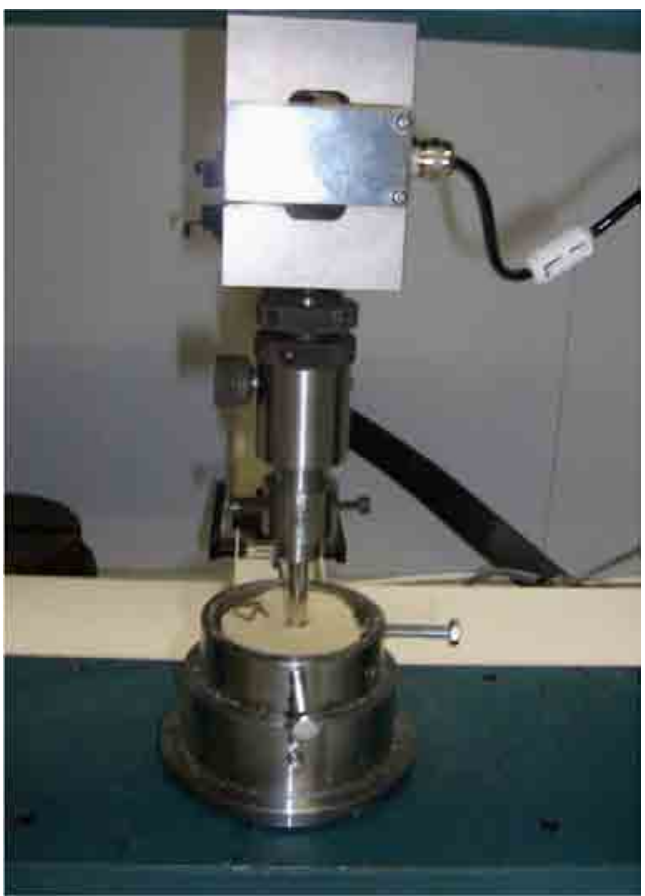

Figure 2: Implant / Synthetic Bone Construct in Position for Pushout Testing

implants as the most common mode of failure with the dynamic hip screw is 'cut-out'. In performing push out tests, the different force displacement curves produced by each implant were recorded. The amount of energy required to failure was also recorded. The implant that required the greatest amount of energy to advance it forward through the test material offered the greater resistance to 'cut-out'. In clinical practice, these implants have to advance through roughly $10 \mathrm{~mm}$ of bone before they 'cut out' through a femoral head.

In performing the push out tests, a load was applied to the implants via the crosshead of the Tinius Olsen Tensile testing machine (Figure 2) and as the implants advanced into the test material; the forcedisplacement curve was recorded, as demonstrated in Figures 3 and 4. The peak force or push out force on a force-displacement curve is the force at which the implant starts to move relative to the surrounding test material. This is the force at which failure occurs at the bone implant interface. Push out tests were performed at a strain rate of $2 \mathrm{~mm} / \mathrm{min}$ and were stopped after failure or a displacement of $10 \mathrm{~mm}$. Custom designed jigs were used to secure both the implants and the test specimens ensuring that the only movement that could occur was at the interface between the implant and the test material.

The study design involved using two different synthetic bone substrates in the form of polyurethane foam blocks as the test materials. These were chosen because they can be used as an alternative test medium for human cancellous bone as they are consistent and uniform materials with properties in the range of human cancellous bone. The polyurethane blocks that were chosen for this study had mechanical properties as described in Table 1 .

The reason that the polyurethane blocks in Table 1 were chosen for this study was because of previous work by Patel et al. [9] had demonstrated that the $0.16 \mathrm{~g} / \mathrm{cm}^{3}$ material had compressive Young's

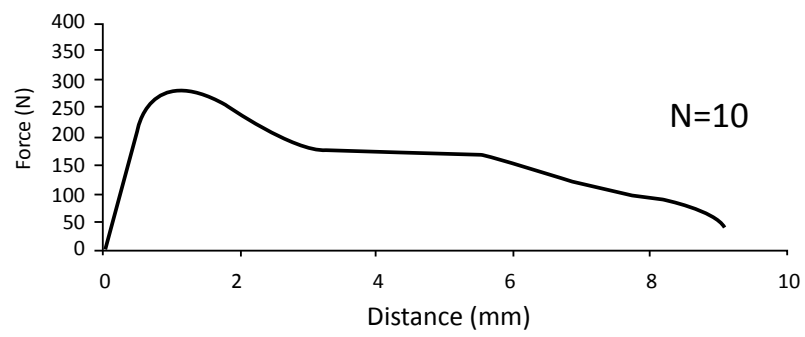

Figure 3: Trendline for Pushout Force Displacement Curves with the DHS in $0.08 \mathrm{~g} / \mathrm{cm} 3$ test material.

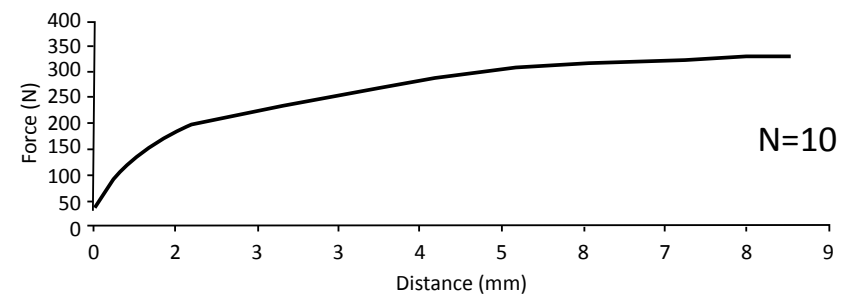

Figure 4: Trendline for Pushout Force Displacement Curves with the X-Bolt in $0.08 \mathrm{~g} / \mathrm{cm} 3$ test material.

\begin{tabular}{|l|c|c|c|c|c|c|c|}
\hline & & \multicolumn{2}{|c|}{ Compressive } & \multicolumn{2}{c|}{ Tensile } & \multicolumn{2}{c|}{ Shear } \\
\hline $\begin{array}{l}\text { Density } \\
\text { pcf }\end{array}$ & $\begin{array}{c}\text { Density } \\
\mathrm{g} / \mathrm{cm}^{3}\end{array}$ & $\begin{array}{c}\text { Strength } \\
\mathrm{MPa}\end{array}$ & $\begin{array}{c}\text { Modulus } \\
\mathrm{MPa}\end{array}$ & $\begin{array}{c}\text { Strength } \\
\mathrm{MPa}\end{array}$ & $\begin{array}{l}\text { Modulus } \\
\mathrm{MPa}\end{array}$ & $\begin{array}{c}\text { Strength } \\
\mathrm{MPa}\end{array}$ & $\begin{array}{c}\text { Modulus } \\
\mathrm{MPa}\end{array}$ \\
\hline 5 & 0.08 & 0.60 & 16 & 1.0 & 32 & 0.59 & 7.1 \\
\hline 10 & 0.16 & 2.2 & 58 & 2.1 & 86 & 1.6 & 19 \\
\hline
\end{tabular}

Table 1: Mechanical Properties of Polyurethane Test Blocks. 
modulus and yield strength values closest to osteoporotic bone and that the $0.08 \mathrm{~g} / \mathrm{cm}^{3}$ material was weaker than osteoporotic bone. Therefore in utilising both materials, it was expected that they would represent two different levels within the spectrum of values for osteoporotic bone. The $0.16 \mathrm{~g} / \mathrm{cm}^{3}$ test material would represent bone from the middle or upper portion of the spectrum for osteoporotic bone and the $0.08 \mathrm{~g} / \mathrm{cm}^{3}$ would represent bone from the lower end of the spectrum.

The synthetic bone samples were prepared by dividing them into test blocks of $60 \times 65 \times 40 \mathrm{~mm}$ and the preparation of these test blocks was undertaken as to mirror clinical practice with the implants being placed to a depth, $10 \mathrm{~mm}$ from the base of each test block. In clinical practice, the ideal position for the X-Bolt within the femoral head is as with the DHS, centre with a tip apex distance of less than $25 \mathrm{~mm}$, It is also worth noting that in clinical practice it is envisaged that the X-Bolt would be opened within the bone under $\mathrm{X}$-ray guidance, therefore it should be easily determined if the X-Bolt is fully opened or not from looking at the images at the time of surgery.

\section{Statistical analysis}

This study was designed so that the dynamic hip screw and X-Bolt groups were independent samples. All variables in the tests other than the implants themselves were equal. Statistical Analysis was performed using PASW Statistics software and P values were calculated with the Mann-Whitney test.

\section{Results}

In Figures 3 and 4, the trendlines for the force displacement curves obtained for the push out studies performed with the DHS and the $\mathrm{X}$-Bolt in the $0.08 \mathrm{~g} / \mathrm{cm}^{3}$ test material are demonstrated. These trendlines were created by fitting a sixth order polynomial to ten individual force displacement curves.

It is clearly evident from figures 3 and 4 that both implants, the DHS and X-Bolt, produce different force displacement curves. Table 2 represents the results from these force displacement curves in numerical form.

The next aspect of this study was to repeat these push out tests with the $0.16 \mathrm{~g} / \mathrm{cm}^{3}$ test material but the X-Bolts failed to open in this material, therefore this test could not be performed.

\begin{tabular}{|c|c|c|c|c|c|c|}
\hline Units & Units & $n$ & DHS & $n$ & X-Bolt & $\begin{array}{l}\text { Statistical } \\
\text { Significance }\end{array}$ \\
\hline $\begin{array}{l}\text { Peak } \\
\text { Force }\end{array}$ & $\begin{array}{l}\text { New- } \\
\text { tons }\end{array}$ & 10 & $335.1+/-23.5$ & 10 & $336.4+/-22.5$ & N.S. \\
\hline $\begin{array}{l}\text { Distance } \\
\text { to Peak } \\
\text { Force }\end{array}$ & $\mathrm{mm}$ & 10 & $1.31+/-0.30$ & 10 & $7.22+/-1.67$ & $p=0.0001$ \\
\hline $\begin{array}{l}\text { Energy } \\
\text { to Peak } \\
\text { Force }\end{array}$ & $\mathrm{kJ}$ & 10 & $275.0+/-80.8$ & 10 & $1879.5+/-440.8$ & $p=0.0001$ \\
\hline $\begin{array}{l}\text { Energy to } \\
2 \mathrm{~mm}\end{array}$ & $\mathrm{~kJ}$ & 10 & $455.6+/-43.2$ & 10 & $333.5+/-81.5$ & $P=0.001$ \\
\hline $\begin{array}{l}\text { Energy to } \\
4 \mathrm{~mm}\end{array}$ & $\mathrm{~kJ}$ & 10 & $848.5+/-90.3$ & 10 & $844.8+/-170.1$ & N.S. \\
\hline $\begin{array}{l}\text { Energy to } \\
6 \mathrm{~mm}\end{array}$ & $\mathrm{~kJ}$ & 9 & $\begin{array}{l}1183.4+/- \\
133.1\end{array}$ & 10 & $1446.3+/-236.0$ & $p=0.014$ \\
\hline $\begin{array}{l}\text { Energy to } \\
8 \mathrm{~mm}\end{array}$ & $\mathrm{~kJ}$ & 9 & $\begin{array}{l}1429.1+/- \\
195.6\end{array}$ & 7 & $2134.3+/-279.6$ & $p=0.0001$ \\
\hline
\end{tabular}

Table 2: Results for Pushout Tests with the DHS and X-Bolt in pcf $5(0.08 \mathrm{~g} / \mathrm{cm} 3)$ test.

Blocks (All Results are +/- Standard Deviation. N.S. = not significant)

\section{Discussion}

The objective of this study was to compare the amount of energy required to bring about failure of the X-Bolt and the Dynamic Hip Screw (DHS) at their point of fixation within bone. The results as represented in Figures 3 and 4 demonstrate that the force displacement curves for the dynamic hip screw and the X-Bolt are vastly different to each other even though both implants reach an average similar peak force. The dynamic hip screw reaches its peak force early in its force displacement curve and then once it has reached its peak force, the force required to advance it forward through the test material dramatically decreases. In contrast, the force displacement curve for the X-Bolt starts off with lower values but as the X-Bolt advances through the test material, the force required to advance it forward gradually increases until the peak force is reached towards the end of the curve. From the results as demonstrated in Figures 3 and 4 and in Table 2, it can be seen that where along the curve that each implant reaches its peak force is the important factor that determines the amount of energy required for each implant to reach its peak force. In analysing this data, a potential problem was encountered with using the energy to peak force as a comparison for these implants, as the peak force on a load displacement curve is defined as the force at which the implant starts to move relative to the surrounding test material but in this study, the X-Bolt had begun to move within the test material before its peak force was reached. Therefore using energy to peak force may not be an accurate means of comparison for these implants, instead calculating the amount of energy required by each implant to reach a set of predetermined points on their force displacement curves was deemed to be a more accurate means of comparison. These results demonstrated that the dynamic hip screw offered the better initial resistance to push out but the X-Bolt offered better resistance to push out the further the implants moved within the $0.08 \mathrm{~g} / \mathrm{cm}^{3}$ test material.

The significance of this result has yet to be fully determined. However the fact that the X-Bolt initially offered less resistance than the DHS may yet prove problematic. However as these are only early studies with the X-Bolt, further more detailed investigations will need to be undertaken to help to determine if the X-Bolt has potential. These further investigations may include push out tests with polyurethane blocks of more than one density, along with pullout and rotational stability tests. Cyclical loading studies would also be of benefit to help determine how the X-Bolt would behave under the cyclical loads that it would experience in the clinical environment. As the X-Bolt, when used in the clinical setting, will be mounted on a side plate, as with the DHS, impaction should occur at the fracture site during the initial stages of cyclical loading as the X-Bolt should freely slide along the barrel of the side plate, as with the DHS and allow impaction unless the $\mathrm{X}$-Bolt is placed incorrectly so as that it fails to slide along the barrel of the side plate. However if correctly sited then the energy required to result in movement within the barrel of the side plate should be less than that required to cause movement at the bone implant interface within the femoral head and impaction should occur with the lag screw sliding within the barrel of the side plate. Even though the X-Bolt did offer less initial resistance to movement than the DHS, this should not be an issue because again if it is correctly sited, less energy should be required to bring about movement within the barrel of the side plate than at the bone implant interface, thus allowing impaction. However as already mentioned what effect this decreased initial resistance to movement has on the fixation achieved by the X-Bolt has yet to be fully established and further work cyclically loading the X-Bolt under clinically relevant conditions may help to determine this. Finally further testing with cadaveric material in the form of femoral heads 
may be beneficial before progressing to clinical trials. The X-Bolt, as already mentioned, should be placed centre in the femoral head with a Tip Apex Distance of less than $25 \mathrm{~mm}$. As part of this research project, a limited number of femoral heads were sourced and the X-Bolt was sited within a few femoral heads to determine what would happen. As there were only a few femoral heads available, the results did not reach statistical significance, therefore these results were omitted from the results section of this paper. The initial findings however were that as the X-Bolt opened within the $9.1 \mathrm{~mm}$ drill hole created in the centre of the femoral head, the surrounding bone was not of equal consistency and the X-Bolt seemed to follow the path of least resistance in opening. This result was that the inferior wing of the $\mathrm{X}$-Bolt which opened against hard bone inferiorly above the calcar seemed to lever against this hard bone and pushes the entire X-Bolt more superiorly in the femoral head into softer cancellous bone. These preliminary findings would suggest that the X-Bolt seemed to be pushed off centre by this inferior wing. However further testing would need to be done to conclusively prove this, but even if this was confirmed as a problem, it could easily be addressed by modifying the X-Bolt such that the inferior wing would open less than the other wings.

This study has however already had an influence on X-Bolt design as the issue with regard to its inability to open within the $0.16 \mathrm{~g} / \mathrm{cm}^{3}$ material was raised with the designers and subsequent $X$-Bolts have been modified to enable them to open within such material. The designers of the X-Bolt made this modification even though they stated that the main purpose of developing the X-Bolt was to enhance the fixation achieved in osteoporotic bone and therefore they were not concerned about the ability of the X-Bolt to deploy in denser bone such as that which would be found in young healthy adults, however they did agree that it should at least be able to deploy in the $0.16 \mathrm{~g} / \mathrm{cm}^{3}$ test material. The designers at the time of testing were also contemplating developing a reamer that would create a space for the X-Bolt to deploy into in the more dense bone if it was deemed that this was necessary. However I would like to comment that if the X-Bolt was going to used clinically then the person using it should ensure that it opens fully or not use it at all. By selecting the patients carefully, i.e. elderly patients with known osteoporosis and an intertrochanteric fracture, this problem should be avoided.

As already mentioned, there have been previous attempts at redesigning the lag screw element of the dynamic hip screw. However this study doesn't completely answer the question with regard to the $\mathrm{X}$-Bolts possible potential as a successful design variation of the dynamic hip screw as further work is necessary. However this study is a start and with the future work that is planned, a more definite answer may be forthcoming.

\section{Conclusion}

The X-Bolt is a new concept as a design variation of the dynamic hip lag screw for the fixation of intertrochanteric fractures. The X-Bolt produces a different force displacement curve than the dynamic hip screw. However further investigations are necessary before the true potential of this new implant is known and whether or not it has potential.

\section{References}

1. Azhar A, Lim C, Kelly E, O'Rourke K, Dudeney S, et al. (2008) Cost induced by hip fractures. Ir Med J 101: 213-215.

2. Koval Kenneth J, Zuckerman Joseph D (1999),Hip Fractures: A Practical Guide to Management.
3. Marks R, Allegrante JP, Ronald MacKenzie C, Lane JM (2003) Hip fractures among the elderly: causes, consequences and control. Ageing Res Rev 2: 57 93.

4. Baumgaertner MR, Curtin SL, Lindskog DM, Keggi JM (1995) The value of the tip-apex distance in predicting failure of fixation of peritrochanteric fractures of the hip. J Bone Joint Surg Am 77: 1058-1064.

5. Davis TR, Sher JL, Horsman A, Simpson M, Porter BB, et al. (1990) Intertrochanteric femoral fractures. Mechanical failure after internal fixation. J Bone Joint Surg Br 72: 26-31.

6. Chirodian N, Arch B, Parker MJ (2005) Sliding hip screw fixation of trochanteric hip fractures: outcome of 1024 procedures. Injury 36: 793-800.

7. Bramlet DG, Wheeler D (2003) Biomechanical evaluation of a new type of hip compression screw with retractable talons. J Orthop Trauma 17: 618-624.

8. Augat $P$, Rapp S, Claes L (2002) A modified hip screw incorporating injected cement for the fixation of osteoporotic trochanteric fractures. J Orthop Trauma 16: 311-316.

9. Patel PS, Shepherd DE, Hukins DW (2008) Compressive properties of commercially available polyurethane foams as mechanical models for osteoporotic human cancellous bone. BMC MusculoskeletDisord 9: 137.

10. Bramlet DG, Wheeler D (2003) Biomechanical evaluation of a new type of hip compression screw with retractable talons. J Orthop Trauma 17: 618-624. 